\title{
The Cyclic Nitronate Route to Pharmaceutical Molecules: Synthesis of GSK's Potent PDE4 Inhibitor as a Case Study
}

\author{
Evgeny V. Pospelov ${ }^{1,2}$, Ivan S. Golovanov ${ }^{1} \mathbb{D}$, Sema L. Ioffe ${ }^{1}$ and Alexey Yu. Sukhorukov ${ }^{1,3, *}$ \\ 1 N.D. Zelinsky Institute of Organic Chemistry, Russian Academy of Sciences, 119991 Moscow, Russia; \\ evpos00@mail.ru (E.V.P.); cell-25@yandex.ru (I.S.G.); iof@ioc.ac.ru (S.L.I.) \\ 2 Department of Chemistry, M.V. Lomonosov Moscow State University, 119991 Moscow, Russia \\ 3 Department of Innovational Materials and Technologies Chemistry, \\ Plekhanov Russian University of Economics, 117997 Moscow, Russia \\ * Correspondence: sukhorukov@ioc.ac.ru; Tel.: +7-499-135-53-29
}

Academic Editor: Nagatoshi Nishiwaki

Received: 3 July 2020; Accepted: 4 August 2020; Published: 8 August 2020

\begin{abstract}
An efficient asymmetric synthesis of GlaxoSmithKline's potent PDE4 inhibitor was accomplished in eight steps from a catechol-derived nitroalkene. The key intermediate (3-acyloxymethyl-substituted 1,2-oxazine) was prepared in a straightforward manner by tandem acylation/(3,3)-sigmatropic rearrangement of the corresponding 1,2-oxazine- $N$-oxide. The latter was assembled by a $(4+2)$-cycloaddition between the suitably substituted nitroalkene and vinyl ether. Facile acetal epimerization at the C-6 position in 1,2-oxazine ring was observed in the course of reduction with $\mathrm{NaBH}_{3} \mathrm{CN}$ in $\mathrm{AcOH}$. Density functional theory (DFT) calculations suggest that the epimerization may proceed through an unusual tricyclic oxazolo(1,2)oxazinium cation formed via double anchimeric assistance from a distant acyloxy group and the nitrogen atom of the 1,2-oxazine ring.
\end{abstract}

Keywords: $\mathrm{C}-\mathrm{H}$ functionalization; total synthesis; pyrrolidines; anchimeric assistance; epimerization; PDE4 inhibitors

\section{Introduction}

Cyclic nitronates (1,2-oxazine- $N$-oxides 1 and isoxazoline- $N$-oxides 2 ) are useful intermediates in the synthesis of complex nitrogen containing scaffolds due to their versatile reactivity as 1,3-dipoles and accessibility from nitroalkenes (Scheme 1a) [1-10]. Denmark's group extensively exploited the inter- and intramolecular $(3+2)$-cycloaddition reactions with six-membered cyclic nitronates 1 to construct various bi- and polycyclic nitroso acetal frameworks 3, which were then converted into fused pyrrolidine derivatives by an intramolecular reductive amination (Scheme 1b) [1,11]. Using this strategy, total syntheses of numerous pyrrolizidine and indolizidine alkaloids [12-14], as well as (5.5.5.5)- and (5.5.5.4)-azafenestanes [15,16], were accomplished.

Our group has a long-term interest in developing another approach towards the modification of cyclic nitronates, which utilizes $\mathrm{C}-\mathrm{H}$ functionalization of the position next to the nitronate group ( $\alpha$-C-atom, Scheme 1c) [17]. Some time ago, we demonstrated that upon silylation, cyclic nitronates 1 and $\mathbf{2}$ are transformed into $N$-siloxyenamines $\mathbf{4}$, in which the double bond is shifted to the exocyclic $\alpha$-position [18]. Enamines 4 exhibit umpolung reactivity and react with nucleophiles in the presence of Lewis acids (LA) to give $\alpha$-substituted cyclic oxime ethers 5 (1,2-oxazines or isoxazolines) via $\mathrm{S}_{\mathrm{N}}{ }^{\prime}$ substitution of TMSO-group (Scheme 1c). Using this approach, nucleophilic halogenation [19], oxygenation [20-22], azidination [23] of cyclic nitronates were performed (route 1). Although we succeeded in using this methodology in the total synthesis of some pharmaceutical molecules, in 
the case of nitronates having acid-sensitive groups (e.g., acetals), it proved to be not very efficient (vide infra) $[20,24,25]$.

a. Synthesis of cyclic nitronates from nitroalkenes

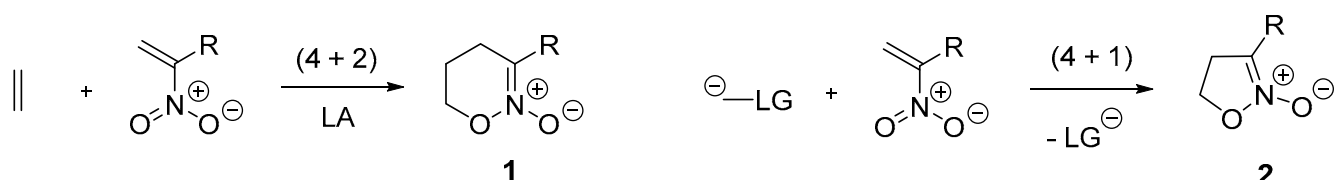

1

b. 1,3-Dipolar addition with cyclic nitronates and its application in total synthesis

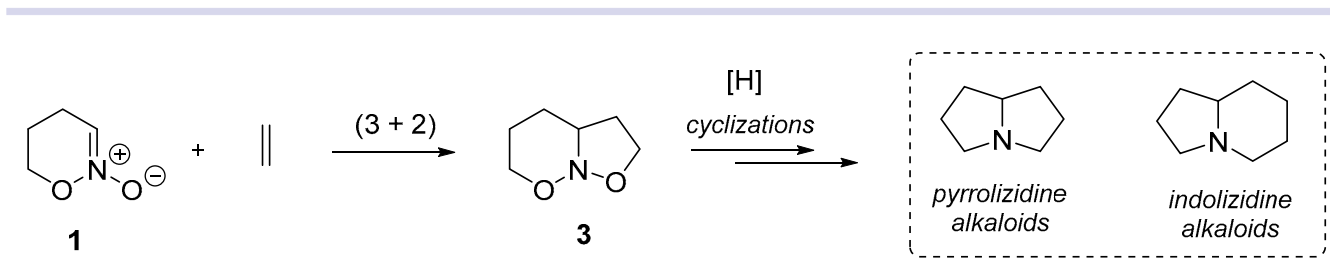

c. $\mathrm{C}$-H functionalization of cyclic nitronates via $\mathrm{N}$-siloxyenamines (route 1)

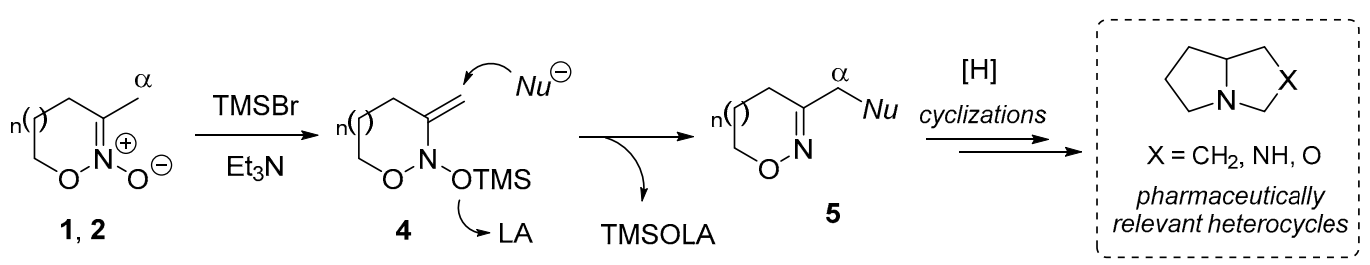

d. C-H functionalization of cyclic nitronates via [3,3]-rearrangement of $\mathrm{N}$-acyloxyenamines (route 2)

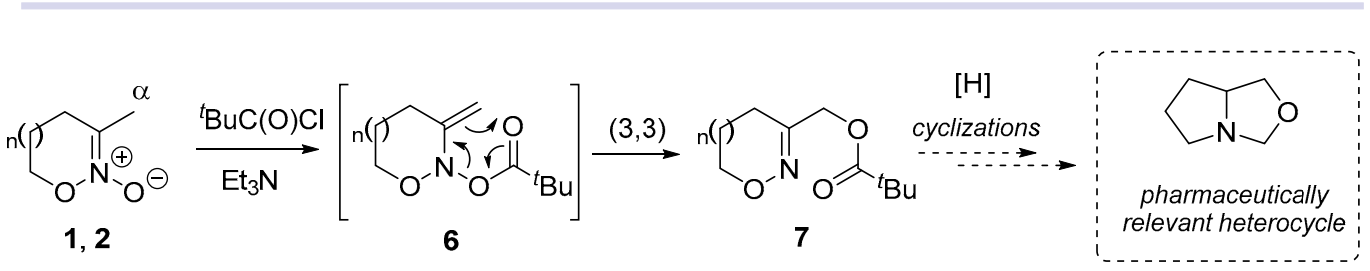

Scheme 1. Approaches towards modification of cyclic nitronates. (a) Synthesis of cyclic nitronates from nitroalkenes; (b) 1,3-Dipolar addition with cyclic nitronates and its application in total synthesis; (c) $\mathrm{C}-\mathrm{H}$ functionalization of cyclic nitronates via $\mathrm{N}$-siloxyenamines (route 1); (d) C-H functionalization of cyclic nitronates via [3,3]-rearrangement of $\mathrm{N}$-acyloxyenamines (route 2).

Recently, we designed another strategy for the site-selective functionalization of cyclic nitronates 1 and $\mathbf{2}$ via acylation with acyl halides/ $\mathrm{Et}_{3} \mathrm{~N}$ (Scheme $1 \mathrm{~d}$ ) [26]. The initially formed $N$-acyloxyenamines 6 undergo a spontaneous (3,3)-rearrangement to give $\alpha$-acyloxy-substituted cyclic oxime ethers 7 (route 2). This tandem $\mathrm{C}-\mathrm{H}$ oxygenation process could be performed under very mild conditions. At present, we are testing the scope and limitation of this method in the total synthesis of some model target molecules to compare its efficacy with our previous $\mathrm{C}-\mathrm{H}$ functionalization methods. In this study, a potent GlaxoSmithKline's phosphodiesterase 4 (PDE4) inhibitor CMPO [27-29], which was previously synthesized using route 1 [24,30], was chosen as a target molecule.

Scheme 2 depicts our previous synthetic route to CMPO. The fused pyrrolidine core was prepared by carbamylation of a trans-3-aryl-substituted prolinol 15. The latter was accessed in our strategy by the reductive contraction of the 1,2-oxazine ring in the intermediate 14, which was prepared by the stereoselective hydride reduction of the 5,6-dihydro- $4 H$-1,2-oxazine 13 [24]. This intermediate was synthesized by the reduction of the $\mathrm{ONO}_{2}$-group in the corresponding nitroxy-substituted 1,2-oxazine 12. Introduction of the nitroxy-group was accomplished by the LA-assisted functionalization of the methyl group in the $N$-oxide 10 using route 1 described above (see Scheme 1c). The required $N$-oxide 
10 was assembled in a stereoselective manner by the $(4+2)$-cycloaddition of nitroalkene 8 with the vinyl ether 9 bearing Whitesell's chiral auxiliary group ((+)-trans-2-phenyl-1-cyclohexanol ether).
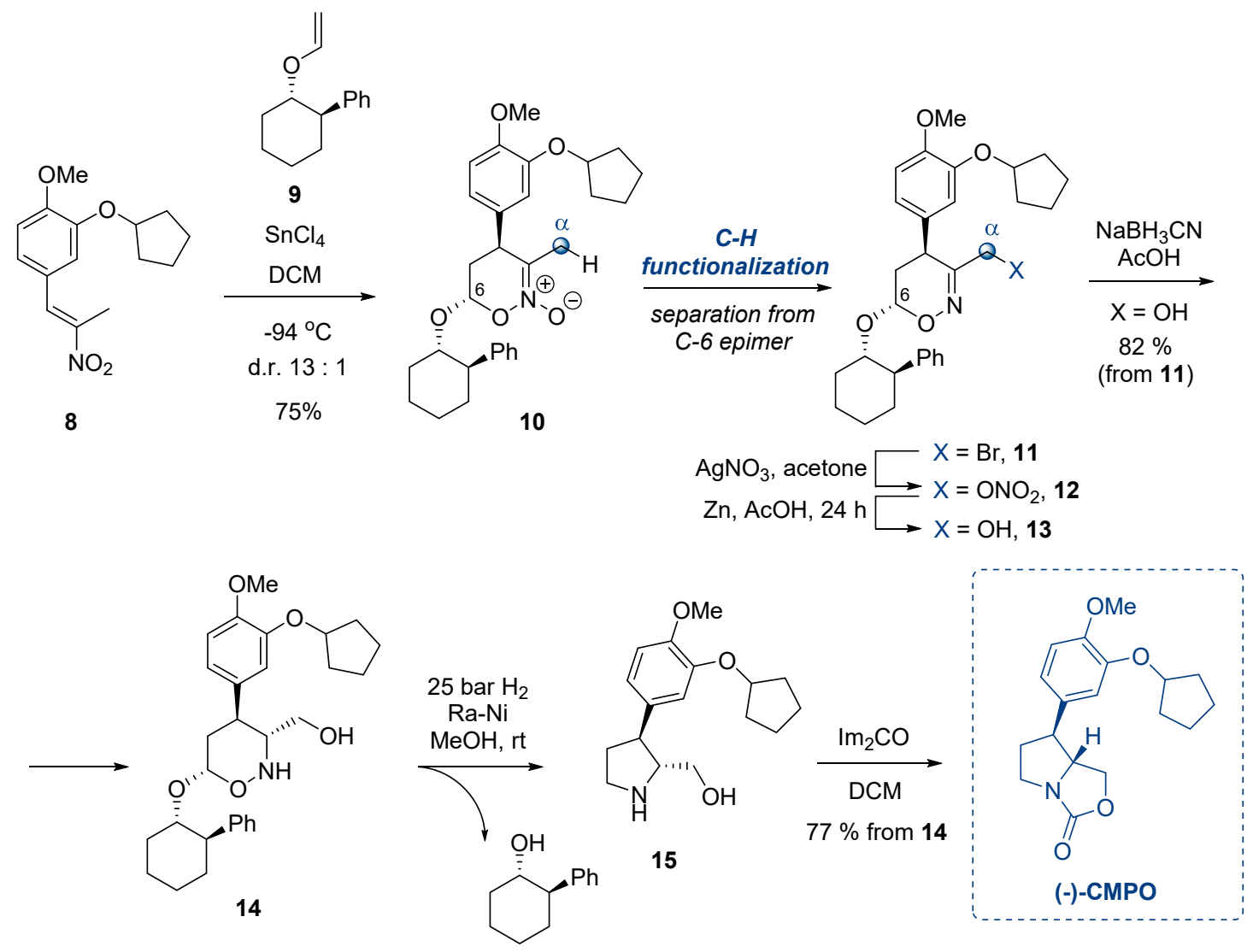

Scheme 2. Previous asymmetric synthesis of (-)-CMPO.

Oxygenation of the methyl group in the $N$-oxide 10 proved to be challenging, and several methods were tested (Scheme 3). $\mathrm{N}$-Siloxy, $\mathrm{N}$-oxyenamine $\mathbf{1 6}$ was generated from the $\mathrm{N}$-oxide $\mathbf{1 0}$ under mild conditions and then subjected to the LA-assisted nucleophilic addition of the bromide anion [24,25]. However, the desired 3-bromomethyl-1,2-oxazine 11, which served as a precursor to nitrate 12, was formed in moderate yields (best results are shown in Scheme 3a). Another issue was the epimerization of the sensitive C-6 acetal stereocenter leading to a mixture of 4,6-trans/4,6-cis-diastereomers $\mathbf{1 1}$ and $\mathbf{1 1}{ }^{\prime}$, which had to be separated by column chromatography (Scheme 3a,b). Unfortunately, the epimer 11' could not be used in the synthesis of CMPO as it produced the undesired 3,4-cis-stereoisomer upon the reduction of the $\mathrm{C}=\mathrm{N}$ bond in 5,6-dihydro- $4 \mathrm{H}-1,2$-oxazine ring on the later stages of the synthesis (Scheme 3c) [25].

The reason for the epimerization may lie in the mechanism of the LA-promoted reaction of $\mathrm{N}$-oxyenamines with nucleophiles, which involves heterolytic cleavage of the $\mathrm{N}-\mathrm{O}$ bond (Scheme $3 \mathrm{~b}$ ). Experimental [20,22] and computational data [22] suggest that the $\mathrm{S}_{\mathrm{N}}$ ' substitution of the TMSO-group may proceed through an epimerizable $\mathrm{N}$-vinyl, $\mathrm{N}$-oxynitrenium cation $\mathrm{C1}$. In our later study, we were able to optimize the epimerization ratio to 6: 1 by using $\mathrm{Cr}\left(\mathrm{NO}_{3}\right)_{3}$ as both a mild Lewis acid and the source of the nitrate anion [20]. However, the yield of nitroxy-derivative 12 was still not very high (ca. $40 \%$ from nitronate 10, Scheme 3a). Thus, further optimization of the $\mathrm{C}-\mathrm{H}$ functionalization stage was reasonable. 


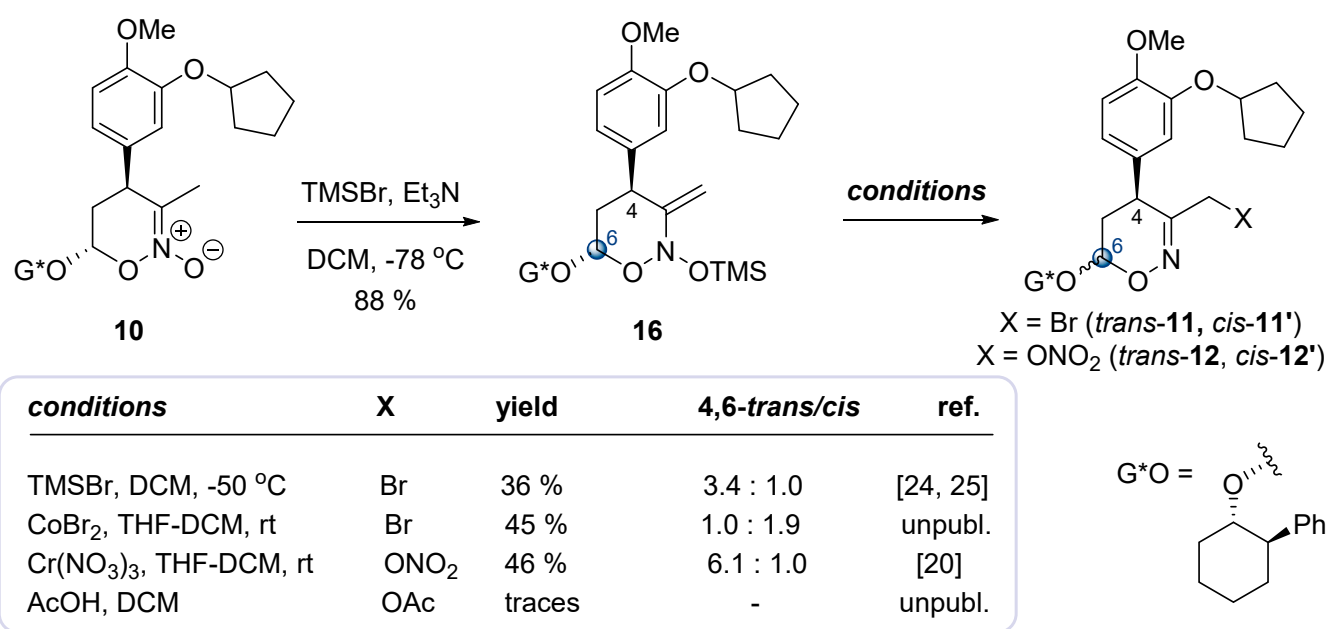

b. Mechanism of epimerization at C-6

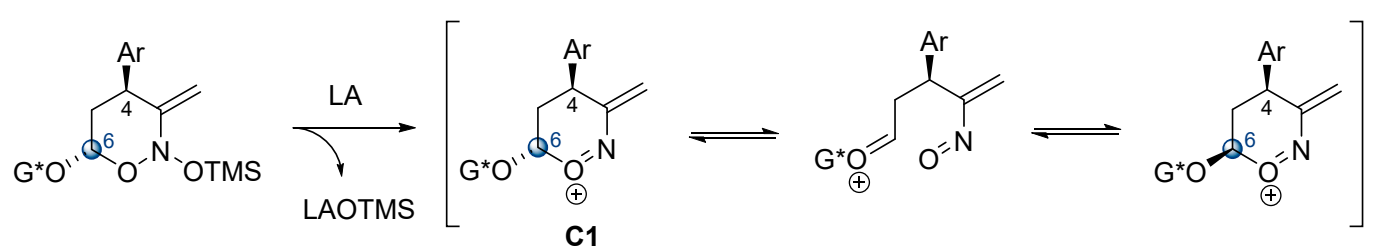

c. Hydride reduction of 4,6-cis-1,2-oxazines<smiles>[X]CC1=NO[C@@H]([O-])C[C@@H]1[AlH2]</smiles><smiles>N#Cc1ccccc1</smiles><smiles>[X]CC1=C([Al])CC([O-])ON1</smiles>

major, undesired<smiles></smiles>

minor, desired

Scheme 3. Problems associated with C-6 epimerization in the LA-assisted functionalization of cyclic nitronate 10. (a) Functionalization of cyclic nitronate 10; (b) Mechanism of epimerization at C-6; (c) Hydride reduction of 4,6-cis-1,2-oxazines.

\section{Results}

We speculated that the pericyclic $(3,3)$-rearrangement of $N$-acyloxyenamine intermediate I1 generated by the acylation of nitronate $\mathbf{1 0}$ may proceed without any epimerization of the C-6 stereogenic center. To test this idea, cyclic nitronate 10 was treated with pivaloyl chloride/ $\mathrm{Et}_{3} \mathrm{~N}$ (1.5/2.0 equiv.) under conditions previously optimized for model 1,2-oxazine- $N$-oxides ( $\mathrm{MeCN},-30{ }^{\circ} \mathrm{C}, 2 \mathrm{~h}$ ) [26]. The desired pivalate 17 was formed in a $61 \%$ yield together with some amount of unreacted $\mathrm{N}$-oxide 10. After a short optimization of conditions, we found that the use of a bigger access of the PivCl/Et $3 \mathrm{~N}$ system (2.0/2.5 equiv.) and prolonged reaction time $(18 \mathrm{~h})$ at lower temperature resulted in an increase in the yield up to $76 \%$ (Scheme 4). Gratifyingly, no noticeable epimerization at the C-6 position was observed under these conditions.

We further investigated whether pivalate $\mathbf{1 7}$ could be used in the synthesis of CMPO. Hydrogenolysis of the pivalate group in 17 (to give alcohol 13) prior the reduction is challenging since 5,6-dihydro-4H-1,2-oxazines are known to undergo fragmentation via a retro-[4+2]-cycloaddition process under the action of bases [31]. Therefore, pivalate $\mathbf{1 7}$ was subjected to the hydride reduction with $\mathrm{NaBH}_{3} \mathrm{CN}$ in acetic acid (Scheme 5). Surprisingly, the reaction produced two separable isomeric products 18 and $18^{\prime}$ in 3: 1 ratio (62\% combined yield, $91 \%$ based on converted 17). From the coupling constants in ${ }^{1} \mathrm{H}-\mathrm{NMR}$ spectra, it was deduced that both isomers had trans-arrangement of the 
substituents at the C-3 and C-4 atoms, while the configuration of the C-6 stereocenter was different. Thus, the C-6 acetal moiety underwent epimerization in the course of the reduction (see Discussion section). The amount of 4,6-cis-isomer $\mathbf{1 8}^{\prime}$ increased with time, demonstrating that the isomerization took place in the reduced product 18 and not in the starting compound 17 . This is also confirmed by the fact that stereisomers 18 and $18^{\prime}$ had same configuration of the newly formed C-3 stereocenter. If the epimerization preceded the reduction, the C-6 epimerized 5,6-dihydro- $4 \mathrm{H}-1,2$-oxazine $\mathbf{1 7}^{\prime}$ would also give the reduced product with the 3,4-cis-disposition of substituents (see Scheme 3c).

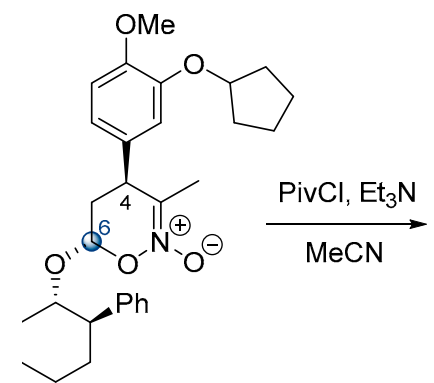

$(+)-10$ rac-10

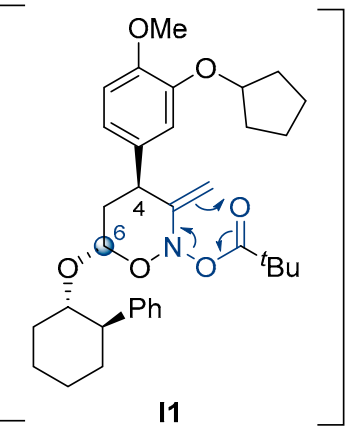

I1
$(3,3)$<smiles>COc1ccc([C@H]2CO[C@H](O[C@H]3CCCC[C@H]3Pc3ccccc3)C2)cc1OC1CCCC1</smiles>

no epimerization at C- 6 no oxygenation of $\mathrm{C}-4$

\begin{tabular}{|c|c|c|c|}
\hline conditions & 10/PivCI/Et ${ }_{3} N$ (equiv.) & yield of 17 & $\begin{array}{l}\text { no epimerization at } C-6 \\
\text { no oxygenation of } C-4\end{array}$ \\
\hline$-30^{\circ} \mathrm{C}, 1.5 \mathrm{~h}$ & $1.0: 1.5: 2.0$ & $61 \%$ & \\
\hline-40 to $-25^{\circ} \mathrm{C}, 18 \mathrm{~h}$ & $1.0: 2.0: 2.5$ & $76 \%$ & \\
\hline
\end{tabular}

Scheme 4. Tandem acylation/(3,3)-rearrangement of nitronate $\mathbf{1 0 .}$<smiles>[R]OCC1=NO[C@@H](O[C@H]2CCCC[C@@H]2Pc2ccccc2)C[C@H]1c1ccc(OC)c(OC2CCCC2)c1</smiles>

$17, \mathrm{R}=\mathrm{Piv}$ $13 \mathrm{R}=\mathrm{H}$

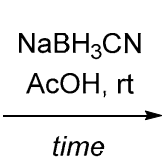

time<smiles>c1ccccc1</smiles>

18, $R=$ Piv 14, $R=H$ (ref. [24])<smiles>[R]OC[C@@H]1NO[C@@H](O[C@@H]2CCCC[C@@H]2P)C[C@H]1c1ccc(OC)c(OC2CCCC2)c1</smiles>

18', R = Piv

14 $^{\prime} \mathrm{R}=\mathrm{H}$ (not observed, ref. [24])

\begin{tabular}{lcc} 
time & d.r. 18/18' & Yield (18 + 18') \\
\hline $30 \min$ & $3: 1$ & $62 \%{ }^{*}$ \\
$100 \mathrm{~min}$ & $1: 1.4$ & $61 \%$ \\
* $91 \%$ based on converted 17 &
\end{tabular}

Scheme 5. Cyanoborohydride reduction of 3-hydroxymethyl 1,2-oxazine $\mathbf{1 3}$ and its pivalate 17.

Isomers 18 and $18^{\prime}$ could be almost equally used in the reductive contraction of the 1,2-oxazine ring [32], since both produced the same amino aldehyde intermediate $\mathbf{I} 3$ upon cleavage of the $\mathrm{N}-\mathrm{O}$ bond followed by fragmentation of the hemiacetal $\mathbf{2} 2$ (Scheme 6). Subsequent intramolecular reductive amination in the intermediate $\mathbf{I} 3$ and protection with the Boc-group afforded the desired prolinol ester 19. Hence, the separation of epimers $\mathbf{1 8}$ and $\mathbf{1 8}$ ' was not required and a mixture could be converted into the product 19 in a 61\% yield. The chiral auxiliary alcohol (trans-2-phenylcyclohexanol) was recovered at this stage in $77 \%$ yield. 


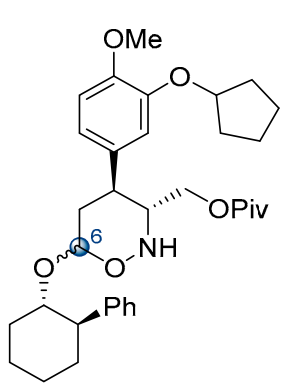

18 orland 18

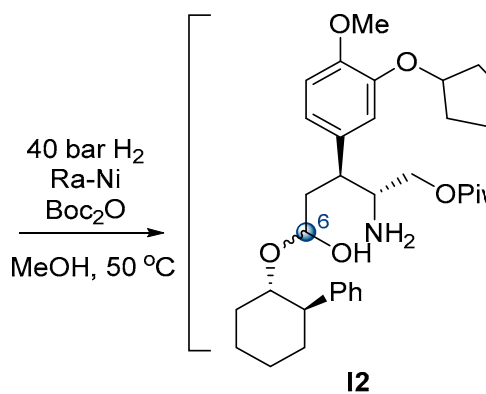

12

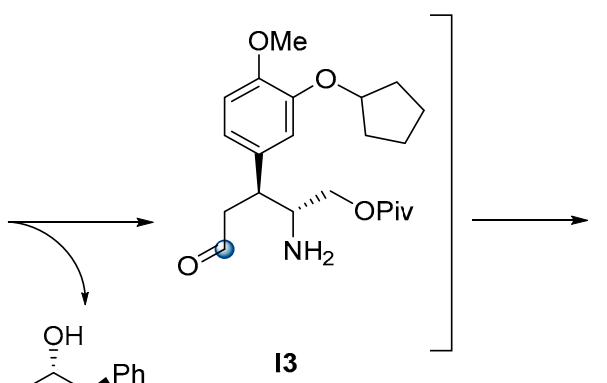

$77 \%$ from 18

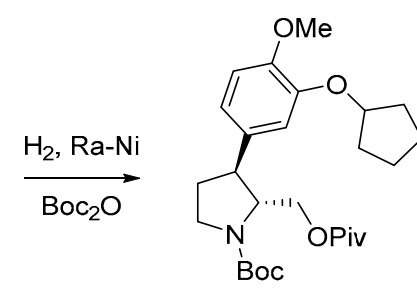

19

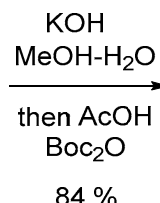

$84 \%$

$74 \%$ from 18 $60 \%$ from 18

Scheme 6. Conversion of 1,2-oxazines $\mathbf{1 8}$ and $\mathbf{1 8}^{\prime}$ into target PDE4 inhibitor (-)-CMPO.

On the next step, careful saponification of the pivalate moiety in pyrrolidine 19 with $\mathrm{KOH}$ in aqueous methanol gave Boc-prolinol 20 in 84\% yield (Scheme 6). It is noteworthy that hydrolysis of the Boc-group was also observed to some extent under these conditions. For this reason, the reaction mixture was treated with $\mathrm{Boc}_{2} \mathrm{O}$ after neutralization to convert the unprotected prolinol into the $N$-Boc-derivative 20, which was isolated by column chromatography.

Finally, deprotection of the N-Boc moiety with TFA and treatment of the resulting prolinol trifluoroacetate with $\mathrm{Im}_{2} \mathrm{CO} / \mathrm{Et}_{3} \mathrm{~N}$ afforded the desired PDE4 inhibitor CMPO (Scheme 6). Thus, the asymmetric synthesis of PDE4 inhibitor CMPO was completed in seven steps from a known nitroalkene 8 in $8 \%$ overall yield. Chiral HPLC analysis revealed the enantiomeric purity of the product $>97 \%$ ee. The racemic sample of CMPO for HPLC analysis was prepared according to the same synthetic sequence starting from the racemic trans-2-phenylcyclohexanol.

\section{Discussion}

Epimerization of the acetal moiety in the course of the hydride reduction of 5,6-dihydro-4-H-1,2-oxazine $\mathbf{1 7}$ is of special note. In the previously reported hydride reduction of 1,2-oxazine 13 possessing a free hydroxymethyl group, no epimerization at the C-6 atom was observed (cf. data in Scheme 2; Scheme 5) [24]. We hypothesized that such a difference in the behavior of 3-hydroxymethyl- and 3-acyloxymethyl-substituted 1,2-oxazines 13 and 17 may be attributed to an anchimeric assistance from the carbonyl group, which stabilizes the intermediate cation C2 [33] by forming a bridged system with an eight-membered ring (cation C3). In carbohydrates, a similar anchimeric assistance of the acyloxy group from the distant 1,4-position has been proposed, yet it was not confirmed unambiguously by experimental data [34-37]. In our case, density functional theory (DFT) calculations at the MN15/Def2TZVP level of theory (see Supplementary material for details) revealed that the bridged cation $\mathbf{C} 3$ is much less stable compared to the initial monocyclic cation $\mathbf{C 2}$. Interestingly, the formation of a third ring between the nitrogen atom and the acyloxy group may lead to a tricyclic cation $\mathbf{C 4}$, which is predicted to be much more stable than the mono- or bicyclic structures C2 and C3 (Scheme 7). The formation of such a stable tricyclic cation as an intermediate or a resting state may account for the observed facile epimerization of pivalate 18 . The higher thermodynamic 
stability of the 4,6-cis-isomer $\mathbf{1 8}^{\prime}$ over the 4,6-trans-isomer $\mathbf{1 8}$, as shown by DFT calculations, is likely to be the driving force for the epimerization at the C- 6 atom.

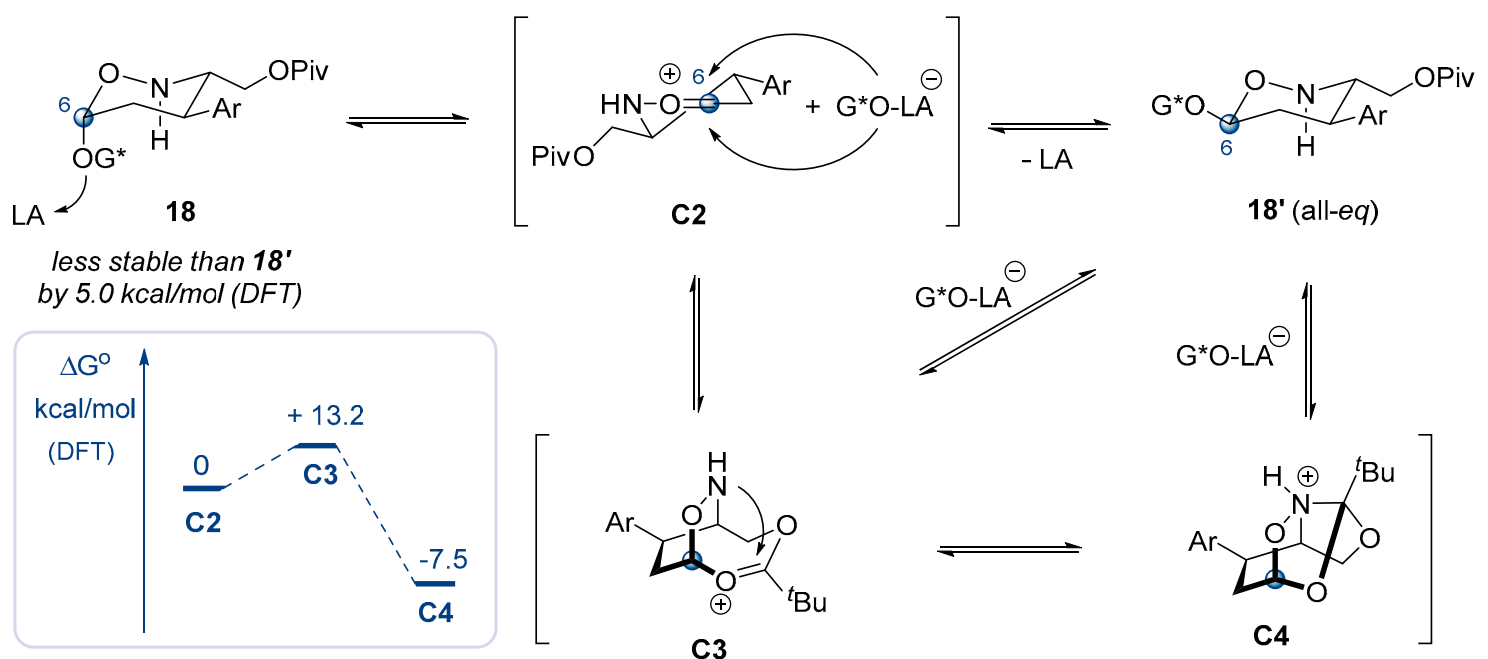

Scheme 7. Plausible mechanism of the epimerization at the C-6 position in 1,2-oxazine 18. Ar - 4-methoxy-3-cyclopentyloxyphenyl, G*-trans-2-phenylcyclohexyl. DFT calculations: MN15/Def2TZVP (AcOH, smd), LA was not included in the calculations.

Another remarkable observation was that 1,2-oxazine 18 (as well as its precursor 17) did not undergo epimerization in acetic acid ( $\mathrm{rt}, 2 \mathrm{~h}$ ). Isomerization to the cis-isomer $\mathbf{1 8}^{\prime}$ was observed only in the presence of $\mathrm{NaBH}_{3} \mathrm{CN}$. Hence, the fragmentation of the acetal moiety is most likely promoted by some Lewis acidic boron species generated from $\mathrm{NaBH}_{3} \mathrm{CN}$ in acidic medium. Indeed, slow epimerization of 1,2-oxazine 18 was observed upon treatment of 18 with $\mathrm{B}(\mathrm{OBu})_{3} \mathrm{Or} \mathrm{BF}_{3} \cdot \mathrm{Et}_{2} \mathrm{O}$ in acetic acid.

It is noteworthy that an anchimeric-assisted epimerization in 1,2-oxazine series has not been reported previously. Moreover, to our knowledge, this is the first reported example of a remote neighboring group participation from the 1,4-position in a six-membered ring confirmed by DFT calculations [38-40]. The formation of an eight-membered ring in this case may be driven by an unusual secondary anchimeric interaction involving the nitrogen atom of the 1,2-oxazine ring leading to an unusual tricyclic oxazolo(1,2)oxazinium cation $\mathbf{C} 4$.

\section{Materials and Methods}

All reactions were carried out in oven-dried $\left(150{ }^{\circ} \mathrm{C}\right)$ glassware. NMR spectra (Bruker AM 300 spectrometer, Karlsruhe, Germany) were recorded at room temperature (if not stated otherwise) with residual solvents peaks as an internal standard. Peak multiplicities are indicated by s (singlet), $\mathrm{d}$ (doublet), $\mathrm{t}$ (triplet), dd (doublet of doublets), q (quartet), quint (quintet), ddd (doublet of doublets of doublets), tt (triplet of triplets), tdd (triplets of doublets of doublets), m (multiplet), br (broad). The numeration of atoms used in the assignment of NMR spectra is given in Figure 1.

HRMS were measured on the electrospray ionization (ESI) (Bruker MicroTOF, Karlsruhe, Germany) instrument with a time-of-flight (TOF) detector. Concentrations c in optical rotation angles are given in $\mathrm{g} / 100 \mathrm{~mL} .[\alpha]_{\mathrm{D}}$ values are given in $10^{-1} \mathrm{deg} \mathrm{cm}^{2} \mathrm{~g}^{-1}$. Column chromatography was performed using Kieselgel (Merck, Germany) 40-60 $\mu \mathrm{m}$ 60A. Analytical thin-layer chromatography was performed on silica gel plates with QF 254. Visualization was accomplished with UV light and solution of anisaldehyde $/ \mathrm{H}_{2} \mathrm{SO}_{4}$ in ethanol. Chiral HPLC analysis was performed on a chromatograph with a UV-VIS photodiode array detector (Shimadzu LC-20, Shimadzu, Japan). All reagents were commercial grade and used as received. $\mathrm{Et}_{3} \mathrm{~N}$, dichloromethane (DCM), and $\mathrm{MeCN}$ were distilled over $\mathrm{CaH}_{2}$ prior to the experiments; $\mathrm{MeOH}$, hexane and ethyl acetate were distilled without drying agents. 

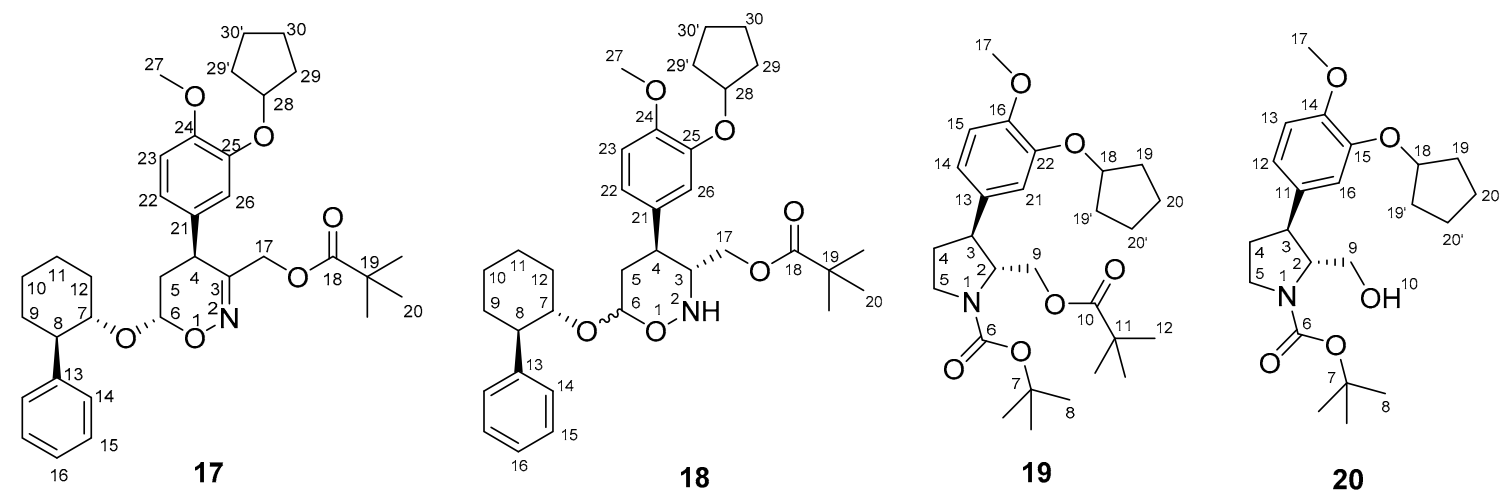

Figure 1. Numeration of atoms in products 17-20.

(+)-(4S,6S)-4-(3-(Cyclopentyloxy)-4-methoxyphenyl)-3-methyl-6-(((1S,2R)-2-phenylcyclohexyl)oxy)-5, 6-dihydro-4H-1,2-oxazine 2-oxide (+)-10 and the corresponding racemate rac-10 were synthesized according to the previously reported procedure from nitroalkene 8 and vinyl ether 9 [25]. In most experiments, very similar yields in enantiomeric and racemic series were obtained. In Schemes and Procedures, the best yields among two series are given if not otherwise stated.

Oxygenation of nitronate 10. Enantipure or racemic nitronate $10(347 \mathrm{mg}, 0.72 \mathrm{mmol})$ was dissolved in dry acetonitrile $(1.7 \mathrm{~mL})$ in a Schlenk tube under argon atmosphere, and then $\mathrm{Et}_{3} \mathrm{~N}(251 \mu \mathrm{L}$, $1.8 \mathrm{mmol})$ was added. The solution was cooled to $-40^{\circ} \mathrm{C}$ and pivaloyl chloride $(174 \mu \mathrm{L}, 1.41 \mathrm{mmol})$ was added. The reaction mixture was stirred at ca. $-40^{\circ} \mathrm{C}$ for $2 \mathrm{~h}$ and then kept in a freezer $\left(\mathrm{ca} .-25^{\circ} \mathrm{C}\right)$ overnight. The mixture was diluted with EtOAc $(5 \mathrm{~mL})$ and transferred into a separating funnel containing EtOAc $(20 \mathrm{~mL})$ and $0.25 \mathrm{M}$ aq. $\mathrm{NaHSO}_{4}$ solution $(20 \mathrm{~mL})$. The aqueous layer was extracted with EtOAc $(20 \mathrm{~mL})$, the combined organic layers were washed with water $(30 \mathrm{~mL})$ and brine $(30 \mathrm{~mL})$, dried over anhydrous $\mathrm{Na}_{2} \mathrm{SO}_{4}$ and concentrated under reduced pressure. The residue was subjected to a column chromatography on silica gel (Hexane/EtOAc $=10 / 1)$ to give $311 \mathrm{mg}(76 \%)$ of enantiopure or racemic pivalate 17 .

$(1 S, 2 R, 4 S, 6 S)$ - and $\left(1 S^{*}, 2 R^{*}, 4 S^{*}, 6 S^{*}\right)$-(4-(3-(cyclopentyloxy)-4-methoxyphenyl)-6-((2-phenylcyclohexyl) oxy)-5,6-dihydro-4H-1,2-oxazin-3-yl)methyl pivalate (17). $\mathrm{R}_{\mathrm{f}}=0.44$ (hexane/EtOAc $=3 / 1$ ). ${ }^{1} \mathrm{H}-\mathrm{NMR}$ (300 MHz, COSY, HSQC, $\left.\mathrm{CDCl}_{3}\right) \delta 7.41-7.13$ (m, 5H, H14, H15, H16), 6.75 (d, J = 8.2 Hz, 1H, H23), $6.57(\mathrm{dd}, J=8.2,2.1 \mathrm{~Hz}, 1 \mathrm{H}, \mathrm{H} 22), 6.53(\mathrm{~d}, J=2.2 \mathrm{~Hz}, 1 \mathrm{H}, \mathrm{H} 26), 5.36(\mathrm{dd}, J=2.7,2.5 \mathrm{~Hz}, 1 \mathrm{H}$, $\left.\mathrm{H}_{\mathrm{eq}} 6\right), 4.71(\mathrm{~m}, 1 \mathrm{H}, \mathrm{H} 28), 4.08$ (d, $\left.J=13.5 \mathrm{~Hz}, 1 \mathrm{H}, \mathrm{H} 17^{\prime}\right), 4.02\left(\mathrm{ddd}, J=10.3,10.2,4.0 \mathrm{~Hz}, 1 \mathrm{H}, \mathrm{H}_{\mathrm{ax}} 7\right)$, $3.98\left(\mathrm{~d}, J=13.5 \mathrm{~Hz}, 1 \mathrm{H}, \mathrm{H} 17^{\prime \prime}\right), 3.80(\mathrm{~s}, 3 \mathrm{H}, \mathrm{H} 27), 2.92\left(\mathrm{dd}, J=11.9,7.7 \mathrm{~Hz}, 1 \mathrm{H}, \mathrm{H}_{\mathrm{ax}} 4\right), 2.61(\mathrm{ddd}, J=11.1$, 10.3, 3.6 Hz, 1H, $\mathrm{H}_{\mathrm{ax}} 8$ ), 2.37 (m, 1H, H12), 2.01 (ddd, $J=13.0,7.7,2.7 \mathrm{~Hz}, 1 \mathrm{H}, \mathrm{H}_{\mathrm{eq}} 5$ ), 1.98-1.73 (m, 10H, Hax 5 , H9' , H10, H29, H30'), 1.70-1.52 (m, 3H, H9", H30"), 1.50-1.28 (m, 3H, H11, Heq 12), 1.10 (s, 9H, H20). ${ }^{13} \mathrm{C}-\mathrm{NMR}\left(75 \mathrm{MHz}, \mathrm{HSQC}, \mathrm{CDCl}_{3}\right) \delta 177.4$ (C18), 155.3 (C3), 149.3 and 147.9 (C24 and C25), 144.4 (C13), 131.1 (C21), 128.0 and 127.8 (2 C14 and 2 C15), 125.9 (C16), 120.7 (C22), 114.9 (C26), 112.2 (C23), 91.0 (C6), 80.4 (C28), 76.1 (C7), 63.6 (C17), 56.1 (C27), 50.7 (C8), 38.6 (C19), 34.3 (C9), 33.8 (C4), 32.8 and 32.7 (C29 and C29'), 32.5 (C5), 30.6 (C12), 27.1 (3 C20), 26.1 (C11), 24.7 (C10), 24.0 (C30 and C30'). HRMS (ESI): $\mathrm{m} / z$ calcd. for $\left[\mathrm{C}_{34} \mathrm{H}_{46} \mathrm{NO}_{6}\right]^{+} 564.3320$, found $564.3316[\mathrm{M}+\mathrm{H}]^{+}$.

$(+)-(1 S, 2 R, 4 S, 6 S)-17$. Colorless oil. $[\alpha]_{D}=+188.6\left(\mathrm{c}=0.09\right.$, EtOAc, $\left.20^{\circ} \mathrm{C}\right)$. rac-17. Colorless oil.

Hydride reduction of 5,6-dihydro-4H-1,2-oxazine 17. Procedure 1: Enantiopure or racemic pivalate $17(80 \mathrm{mg}, 0.14 \mathrm{mmol})$ was dissolved in acetic acid $(0.8 \mathrm{~mL})$ and sodium cyanoborohydride $(120 \mathrm{mg}$, $1.9 \mathrm{mmol}$ ) was added to the solution upon intensive stirring. The reaction mixture was stirred under argon for $30 \mathrm{~min}$ at $\mathrm{rt}$, then diluted with EtOAc $(3 \mathrm{~mL})$ and transferred into a separating funnel containing EtOAc $(20 \mathrm{~mL})$ and a sat. aq. $\mathrm{NaHCO}_{3}$ solution $(20 \mathrm{~mL})$. The aqueous layer was extracted with EtOAc $(20 \mathrm{~mL})$. The combined organic layers were washed with sat. aq. $\mathrm{NaHCO}_{3}$ solution $(20 \mathrm{~mL})$ and brine $(40 \mathrm{~mL})$, then dried over $\mathrm{Na}_{2} \mathrm{SO}_{4}$ and concentrated under reduced pressure. The residue was subjected to a column chromatography on silica gel (Hexane/EtOAc $=10 / 1 \rightarrow 5 / 1 \rightarrow 3 / 1$ ) to yield 
$49 \mathrm{mg}(62 \%)$ of a mixture of 1,2-oxazines 18 and $\mathbf{1 8}^{\prime}$ (d.r. 3: 1). Also, $26 \mathrm{mg}(33 \%)$ of unreacted pivalate 17 was isolated from the column chromatography.

Procedure 2: Enantiopure or racemic pivalate $17(190 \mathrm{mg}, 0.34 \mathrm{mmol})$ was dissolved in acetic acid $(1.8 \mathrm{~mL})$ and sodium cyanoborohydride $(250 \mathrm{mg}, 3.97 \mathrm{mmol})$ was added to the solution upon intensive stirring. The reaction mixture was stirred under argon at $\mathrm{rt}$ for $1.7 \mathrm{~h}$, then diluted with EtOAc $(3 \mathrm{~mL})$ and transferred into a separating funnel containing EtOAc $(20 \mathrm{~mL})$ and a sat. aq. $\mathrm{NaHCO}_{3}$ solution $(20 \mathrm{~mL})$. The aqueous layer was extracted with EtOAc $(20 \mathrm{~mL})$. The combined organic layers were washed with sat. aq. $\mathrm{NaHCO}_{3}$ solution $(20 \mathrm{~mL})$ and brine $(40 \mathrm{~mL})$, then dried over $\mathrm{Na}_{2} \mathrm{SO}_{4}$ and concentrated under reduced pressure. The residue was subjected to a column chromatography on silica gel (Hexane/EtOAc $=10 / 1 \rightarrow 5 / 1 \rightarrow 3 / 1)$ to yield $48 \mathrm{mg}(25 \%)$ of the fast moving isomer 18 and $69 \mathrm{mg}(36 \%)$ of the slow moving isomer $1 \mathbf{8}^{\prime}$.

$\left((3 R, 4 S, 6 S)\right.$ - and $\left(3 R^{*}, 4 S^{*}, 6 S^{*}\right)-4-(3-(C y c l o p e n t y l o x y)-4-m e t h o x y p h e n y l)-6-(((1 S, 2 R)-2-p h e n y l c y c l o h e x y l)$ oxy)-1,2-oxazinan-3-yl)methyl pivalate (18). Colorless oil (both enantiopure and racemic). $R_{\mathrm{f}}=0.37$ (hexane/EtOAc = 3/1). ${ }^{1} \mathrm{H}-\mathrm{NMR}\left(300 \mathrm{MHz}, \mathrm{COSY}, \mathrm{HSQC}, \mathrm{CDCl}_{3}\right) \delta 7.55-7.32(\mathrm{~m}, 4 \mathrm{H}, \mathrm{H} 14, \mathrm{H} 15)$, 7.29-7.21 (m, 1H, H16), $6.76(\mathrm{~d}, J=8.0 \mathrm{~Hz}, 1 \mathrm{H}, \mathrm{H} 23), 6.61(\mathrm{dd}, J=8.0,2.1 \mathrm{~Hz}, 1 \mathrm{H}, \mathrm{H} 22), 6.59$ (br s, $1 \mathrm{H}, \mathrm{H} 26)$, $4.99(\mathrm{~d}, J=3.0 \mathrm{~Hz}, 1 \mathrm{H}, \mathrm{H6}), 4.79-4.68(\mathrm{~m}, 1 \mathrm{H}, \mathrm{H} 28), 4.03\left(\mathrm{br} \mathrm{d}, J=10.7 \mathrm{~Hz}, 1 \mathrm{H}, \mathrm{H}_{\mathrm{ax}} 2\right), 3.80(\mathrm{~s}, 3 \mathrm{H}, \mathrm{H} 27)$, $3.78\left(\mathrm{ddd}, J=10.0,10.0,3.9 \mathrm{~Hz}, 1 \mathrm{H}, \mathrm{H}_{\mathrm{ax}} 7\right), 3.51\left(\mathrm{dd}, J=11.8,2.8 \mathrm{~Hz}, 1 \mathrm{H}, \mathrm{H} 17^{\prime}\right), 3.22(\mathrm{br} \mathrm{ddd}, J=10.7,9.8$, $8.5 \mathrm{~Hz}, 1 \mathrm{H}, \mathrm{H}_{\mathrm{ax}} 3$ ), 3.08 (dd, $\left.J=11.8,8.5 \mathrm{~Hz}, 1 \mathrm{H}, \mathrm{H} 17^{\prime \prime}\right), 2.68$ (ddd, $J=12.3,10.3,3.7 \mathrm{~Hz}, 1 \mathrm{H}, \mathrm{H}_{\mathrm{ax}} 8$ ), 2.32 $\left(\mathrm{ddd}, J=11.9,11.9,4.5 \mathrm{~Hz}, 1 \mathrm{H}, \mathrm{H}_{\mathrm{ax}} 4\right), 2.21\left(\mathrm{br} \mathrm{d}, J=10.6 \mathrm{~Hz}, 1 \mathrm{H}, \mathrm{H}_{\mathrm{ax}} 12\right), 2.05-1.75\left(\mathrm{~m}, 11 \mathrm{H}, \mathrm{H} 5, \mathrm{H} 9^{\prime}, \mathrm{H} 10\right.$, H29, H30'), 1.70-1.54 (m, 3H, H9", H30"), 1.48-1.25 (m, 3H, H11, Heq 12), 1.12 (s, 9H, H20). ${ }^{13} \mathrm{C}-\mathrm{NMR}$ (75 MHz, HSQC, HMBC, DEPT135, $\mathrm{CDCl}_{3}$ ) $\delta 178.1$ (C18), 149.1 and 147.8 (C24 and C25), 144.5 (C13), 133.9 (C21), 128.8 and 128.0 (2 C14 and 2 C15), 126.9 (C16), 119.5 (C22), 114.2 (C26), 112.3 (C23), 93.5 (C6), 80.5 (C28), 77.7 (C7), 63.3 (C17), 60.1 (C3), 56.1 (C27), 50.7 (C8), 38.6 (C19), 37.2 (C4), 37.0 (C5), 33.3 (C9), 32.7 and 32.8 (C29 and C29'), 31.3 (C12), 27.1 (3 C20), 26.0 (C11), 24.8 (C10), 24.0 (C30 and C30'). HRMS (ESI): $m / z$ calcd. for $\left[\mathrm{C}_{34} \mathrm{H}_{48} \mathrm{NO}_{6}\right]^{+} 566.3476$, found $566.3474[\mathrm{M}+\mathrm{H}]^{+}$.

$\left((3 R, 4 S, 6 R)-\right.$ and $\left(3 R^{*}, 4 S^{*}, 6 R^{*}\right)-4-(3-(C y c l o p e n t y l o x y)-4-m e t h o x y p h e n y l)-6-(((1 S, 2 R)-2-p h e n y l c y c l o h e x y l)$ oxy)-1,2-oxazinan-3-yl)methyl pivalate $\left(\mathbf{1 8}^{\prime}\right)$. Characterized in mixture with $\mathbf{1 8}\left(\right.$ d.r. $\left.\mathbf{1 8} / \mathbf{1 8} \mathbf{8}^{\prime}=1: 4\right)$. Colorless oil (both enantiopure and racemic). $\mathrm{R}_{\mathrm{f}}=0.30$ (hexane/EtOAc $\left.=3 / 1\right) .{ }^{1} \mathrm{H}-\mathrm{NMR}(300 \mathrm{MHz}, \mathrm{COSY}, \mathrm{HSQC}$, $\left.\mathrm{CDCl}_{3}\right) \delta$ 7.55-7.32 (m, 5H, H14, H15, H16), 6.79 (d, J = 8.2 Hz, 1H, H23), 6.60 (dd, J = 8.2, 2.2 Hz, $1 \mathrm{H}, \mathrm{H} 22), 6.55(\mathrm{~d}, J=2.2 \mathrm{~Hz}, 1 \mathrm{H}, \mathrm{H} 26), 5.43(\mathrm{~d}, J=10.4 \mathrm{~Hz}, 1 \mathrm{H}, \mathrm{H} 2), 5.28(\mathrm{~d}, J=2.9 \mathrm{~Hz}, 1 \mathrm{H}, \mathrm{H} 6)$, $4.73(\mathrm{~m}, 1 \mathrm{H}, \mathrm{H} 28), 3.93$ (ddd, $J=10.3,10.2,4.0 \mathrm{~Hz}, 1 \mathrm{H}, \mathrm{H} 7), 3.81$ (s, 3H, H27), 3.59 (d, J = $12.9 \mathrm{~Hz}$, 1H, H17), 3.48 (ddd, $J=11.2,10.4,5.7 \mathrm{~Hz}, 1 \mathrm{H}, \mathrm{H}_{\mathrm{ax}} 3$ ), 3.38 (dd, $\left.J=12.9,5.7 \mathrm{~Hz}, 1 \mathrm{H}, \mathrm{H} 17\right), 2.71$ (ddd, $\left.J=10.6,10.3,3.3 \mathrm{~Hz}, 1 \mathrm{H}, \mathrm{H}_{\mathrm{ax}} 8\right), 2.63\left(\mathrm{ddd}, J=12.5,11.2,4.0 \mathrm{~Hz}, 1 \mathrm{H}, \mathrm{H}_{\mathrm{ax}} 4\right), 2.24(\mathrm{br} \mathrm{d}, J=11.9 \mathrm{~Hz}$, $\left.1 \mathrm{H}, \mathrm{H}_{\mathrm{ax}} 12\right), 2.06\left(\mathrm{td}, J=13.3,12.5,2.9 \mathrm{~Hz}, 1 \mathrm{H}, \mathrm{H}_{\mathrm{ax}} 5\right), 1.99-1.76\left(\mathrm{~m}, 10 \mathrm{H}, \mathrm{H}_{\mathrm{eq}} 5, \mathrm{H} 9^{\prime}\right.$, H10, H29, H30'), 1.72-1.53 (m, 3H, H9", H30"), 1.53-1.25 (m, 3H, H11, Heq 12), 1.10 (s, 9H, H20). ${ }^{13} \mathrm{C}-\mathrm{NMR}$ (75 MHz, HSQC, HMBC, DEPT135, CDCl 3 ) $\delta 177.4$ (C18), 149.9 and 148.2 (C24 and C25), 143.7 (C13), 130.6 (C21), 129.6 (C16), 127.7 and 127.5 (2 C14 and 2 C15), 120.0 (C22), 113.7 (C26), 112.4 (C23), 95.2 (C6), 80.7 (C28), 78.5 (C7), 65.8 (C3), 61.3 (C17), 56.0 (C27), 50.5 (C8), 38.5 (C19), 36.7 (C4), 36.4 (C5), 33.1 (C9), 32.8 and 32.7 (C29 and C29'), 30.7 (C12), 27.0 (3 C20), 25.8 (C11), 24.4 (C10), 24.0 (C30 and C30'). HRMS (ESI): $\mathrm{m} / \mathrm{z}$ calcd. for $\left[\mathrm{C}_{34} \mathrm{H}_{48} \mathrm{NO}_{6}\right]^{+} 566.3476$, found $566.3476[\mathrm{M}+\mathrm{H}]^{+}$.

Hydrogenation of 1,2-oxazines 18 and $\mathbf{1 8}$. A glass vial was charged with a solution of enantiopure 1,2-oxazine 18 ( $48 \mathrm{mg}, 0.086 \mathrm{mmol})$ and $\mathrm{Boc}_{2} \mathrm{O}(58 \mathrm{mg}, 0.264 \mathrm{mmol})$ in methanol $(0.5 \mathrm{~mL})$. A suspension of Raney nickel (ca. $100 \mathrm{mg}$, prepared from $50 \%$ slurry in water) in methanol (ca. $0.5 \mathrm{~mL}$ ) was added, and the vial was placed in a steel autoclave, which was then flushed and filled with hydrogen to a pressure of ca. $40 \mathrm{bar}$ and heated to $50{ }^{\circ} \mathrm{C}$. The hydrogenation was conducted for $2 \mathrm{~h}$ with intensive stirring. Then, the autoclave was cooled to rt, slowly depressurized, and the catalyst was removed using a magnet and washed with methanol. The solution was concentrated to dryness under reduced pressure. The residue was subjected to a column chromatography on silica gel (hexane/EtOAc $=20 / 1 \rightarrow 10 / 1)$ to yield $31 \mathrm{mg}(74 \%)$ of $N$-Boc pyrrolidine 19 . The column was then washed with hexane/EtOAc $=5 / 1$ to recover (+)-trans-2-phenylcyclohexanol (12 mg, 77\%). 
Application of the same procedure for the reduction of enantiopure 1,2-oxazine 18' $(69 \mathrm{mg}, 0.13 \mathrm{mmol})$ afforded $36 \mathrm{mg}(60 \%)$ of $\mathrm{N}$-Boc pyrrolidine 19 and $15 \mathrm{mg}(66 \%)$ of (+)-trans-2-phenylcyclohexanol.

Application of the same procedure for the reduction of a mixture of racemic 1,2-oxazines rac-18 and rac-18' (90 mg, $0.159 \mathrm{mmol}$, d.r. 1: 1.4) afforded $46 \mathrm{mg}$ (61\%) of racemic $N$-Boc pyrrolidine rac-19.

Tert-butyl (2R,3S)- and (2R*,3S*)-3-(3-(cyclopentyloxy)-4-methoxyphenyl)-2-((pivaloyloxy)methyl) pyrrolidine-1-carboxylate (19). $\quad R_{f}=0.30$ (hexane/EtOAc $=3 / 1$ ). ${ }^{1} \mathrm{H}-\mathrm{NMR}(300 \mathrm{MHz}, 320 \mathrm{~K}, \mathrm{COSY}$, $\left.\mathrm{HSQC}, \mathrm{CDCl}_{3}\right) \delta 6.82(\mathrm{~d}, J=8.7 \mathrm{~Hz}, 1 \mathrm{H}, \mathrm{H} 15), 6.75-6.70(\mathrm{~m}, 2 \mathrm{H}, \mathrm{H} 14$ and $\mathrm{H} 21), 4.76(\mathrm{~m}, 1 \mathrm{H}, \mathrm{H} 18)$, 4.41-4.26 (m, 1H, H9'), 4.20 (br d, $\left.J=9.9 \mathrm{~Hz}, 1 \mathrm{H}, \mathrm{H9} 9^{\prime \prime}\right), 4.11-3.88$ (br m, 1H, H2), 3.84 (s, 3H, H17), 3.77-3.62 (br m, 1H, H5'), 3.46-3.31 (m, 1H, H5"), 3.29-3.10 (br m, 1H, H3), 2.35-2.18 (m, 1H, H4'), 2.01-1.76 (m, 7H, H4 $\left.{ }^{\prime \prime}, \mathrm{H} 19, \mathrm{H} 20^{\prime}\right), 1.72-1.54$ (m, 2H, H20"), 1.49 (s, 9H, H8), 1.21 (s, 9H, H12). ${ }^{13} \mathrm{C}-\mathrm{NMR}$ (75 MHz, HSQC, DEPT135, $\mathrm{CDCl}_{3}$ ) $\delta 178.2$ (C10), 154.2 (C6), 148.9 and 147.9 (C16 and C22), 135.1 (C13), 119.2 (C14), 114.0 (C21), 112.3 (C15), 80.5 (C18), 80.0 (C7), 63.5 (br, C9), 63.1 (br, C2), 56.2 (C17), 47.2 (C3), 46.3 (C5), 38.8 (C11), 32.8 (C19 and C19'), 31.8 (C4), 28.5 (3 C8), 27.2 (3 C12), 24.0 (C20 and C20') (signals are broadened due to the presence of $N$-Boc rotamers). HRMS (ESI): $m / z$ calcd. for $\left[\mathrm{C}_{27} \mathrm{H}_{42} \mathrm{NO}_{6}\right]^{+}$ 476.3007, found $476.3006[\mathrm{M}+\mathrm{H}]^{+}$.

$(-)-(2 R, 3 S)-19$. Colorless oil, $[\alpha]_{D}=-19.0\left(c=1\right.$, EtOAc, $\left.24^{\circ} \mathrm{C}\right)$. rac-19. Colorless oil.

Saponification of pivalate 19. Enantiopure or racemic pivalate $19(67 \mathrm{mg}, 0.14 \mathrm{mmol})$ was dissolved in $\mathrm{MeOH}(2.8 \mathrm{~mL})$ and a solution of $\mathrm{KOH}(237 \mathrm{mg}, 4.2 \mathrm{mmol})$ in $\mathrm{H}_{2} \mathrm{O}(1.4 \mathrm{~mL})$ was added. The mixture was stirred at room temperature for $24 \mathrm{~h}$. Then, acetic acid $(0.4 \mathrm{~mL})$ was added and the reaction mixture was stirred for $5 \mathrm{~min}$. The resulting solution was concentrated in vacuum. To the residue, $\mathrm{MeOH}$ $(2 \mathrm{~mL})$ and $\mathrm{Boc}_{2} \mathrm{O}(0.065 \mathrm{~g}, 0.28 \mathrm{mmol})$ were added and the resulting solution was stirred for $1 \mathrm{~h}$. Then, volatiles were removed in vacuum and the residue was subjected to a column chromatography on silica gel (hexane/EtOAc $=5 / 1 \rightarrow 3 / 1 \rightarrow 1 / 1)$ to yield $46 \mathrm{mg}(84 \%)$ of prolinol 20.

Tert-butyl (2R,3S)- and (2R*,3S*)-3-(3-(cyclopentyloxy)-4-methoxyphenyl)-2-(hydroxymethyl)pyrrolidine1-carboxylate (20). $R_{f}=0.21$ (hexane/EtOAc $\left.=1 / 1\right) .{ }^{1} \mathrm{H}-\mathrm{NMR}\left(300 \mathrm{MHz}, \mathrm{COSY}, \mathrm{HSQC}, \mathrm{CDCl}_{3}\right) \delta$ $6.81(\mathrm{~d}, J=7.6 \mathrm{~Hz}, 1 \mathrm{H}, \mathrm{H} 13), 6.76(\mathrm{~d}, J=7.6 \mathrm{~Hz}, 1 \mathrm{H}, \mathrm{H} 12), 6.74(\mathrm{~s}, 1 \mathrm{H}, \mathrm{H} 16), 5.13-4.88$ (br, $1 \mathrm{H}$, H10), 4.77 (m, 1H, H18), 3.97-3.85 (br m, 1H, H2), 3.83 (s, 3H, H17), 3.80-3.66 (br m, 2H, H9' , H5'), $3.63\left(\mathrm{dd}, J=11.5,6.8 \mathrm{~Hz}, 1 \mathrm{H}, \mathrm{H9}{ }^{\prime \prime}\right), 3.44-3.27$ (br m, 1H, H5"), $2.89-2.79$ (br m, 1H, H3), 2.22-2.07 (br m, 1H, H4'), 2.02-1.75 (m, 7H, H20' $\left., \mathrm{H} 19, \mathrm{H} 4^{\prime \prime}\right), 1.67-1.57$ (m, 2H, H20' $), 1.51$ (s, 9H, H8). ${ }^{13} \mathrm{C}-\mathrm{NMR}$ (75 MHz, HSQC, DEPT135, CDCl 3 ) $\delta 156.8$ (C6), 149.2 and 147.9 (C14 and C15), 133.3 (C11), 119.7 (C12), 114.5 (C16), 112.3 (C13), 80.5 (C18), 80.4 (C7), 67.1 (C2), 66.1 (C9), 56.2 (C17), 47.4 (C3), 47.0 (C5), 32.9 and 32.8 (C-4, C19 and C19'), 28.5 (3 C8), 24.0 (C20 and C20'). HRMS (ESI): $\mathrm{m} / z$ calcd. for $\left[\mathrm{C}_{22} \mathrm{H}_{33} \mathrm{NO}_{5} \mathrm{Na}^{+}\right.$ 414.2251, found $414.2247[\mathrm{M}+\mathrm{Na}]^{+}$.

$(-)-(2 R, 3 S)-20$. Colorless oil, $[\alpha]_{D}=-9.3\left(c=1\right.$, EtOAc, $\left.24{ }^{\circ} \mathrm{C}\right)$. rac-20. Colorless oil.

Synthesis of (-)- and rac-CMPO. To a stirred solution of enantiopure or racemic prolinol $20(45 \mathrm{mg}$, $0.115 \mathrm{mmol})$ in $\mathrm{DCM}(0.9 \mathrm{~mL})$ was added $\mathrm{CF}_{3} \mathrm{COOH}(0.18 \mathrm{~mL}, 2.4 \mathrm{mmol})$ at $0-5{ }^{\circ} \mathrm{C}$. The cooling bath was removed, and the solution was stirred for $1 \mathrm{~h}$. Then, volatiles were removed under reduced pressure and the residue was dried until constant weight. The resulting trifluoroacetate was dissolved in DCM $(0.85 \mathrm{~mL})$, and $\mathrm{Et}_{3} \mathrm{~N}(0.08 \mathrm{~mL}, 0.58 \mathrm{mmol})$ and 1, $1^{\prime}$-carbonyldiimidazole $(47 \mathrm{mg}, 0.29 \mathrm{mmol})$ were added at rt. The solution was stirred for $18 \mathrm{~h}$ at rt, and then concentrated under reduced pressure. The product was isolated by column chromatography on silica gel (hexane/EtOAc $=3 / 1$ ) followed by recrystallization from hexane \diethyl ether (ca. 1: 1). Yield: $18 \mathrm{mg}(49 \%) .{ }^{1} \mathrm{H}$ NMR spectra were in agreement with previously published data [24].

(-)-(7S,7aR)-CMPO. White solid. Mp $=134-137^{\circ} \mathrm{C}$ (lit.[24] 137-139 ${ }^{\circ} \mathrm{C}$ ). HPLC analysis: ee $>97 \%$ (RT $9.8 \mathrm{~min}$; column CHIRALPAK IA-3 $(15 \mathrm{~cm})$; solvent Hexane $/ \mathrm{i}-\mathrm{PrOH}=90: 10$; temperature $40^{\circ} \mathrm{C}$; flow rate $1 \mathrm{~mL} / \mathrm{min}) .[\alpha]_{\mathrm{D}}=-63.0\left(c=0.5\right.$, EtOAc, $\left.25^{\circ} \mathrm{C}\right)$. lit. [24] $[\alpha]_{\mathrm{D}}=-69.1\left(c=0.83, \mathrm{MeOH}, 26^{\circ} \mathrm{C}\right)$. rac-CMPO. White solid. $\mathrm{Mp}=103-104{ }^{\circ} \mathrm{C}$ (lit.[30] 99-101 $\left.{ }^{\circ} \mathrm{C}\right)$. HPLC analysis: (+)-(7R,7aS)-CMPO (RT $8.8 \mathrm{~min}$ ) and (-)-(7S,7aR)-CMPO (RT $9.8 \mathrm{~min})$; column CHIRALPAK IA-3 $(15 \mathrm{~cm})$; solvent Hexane $/ i-\mathrm{PrOH}=90: 10$; temperature $40^{\circ} \mathrm{C}$; flow rate $1 \mathrm{~mL} / \mathrm{min}$. 


\section{Conclusions}

In conclusion, we were able to solve the problem of site-selective $\mathrm{C}-\mathrm{H}$ oxygenation of the cyclic nitronate intermediate in the asymmetric synthesis of a potent PDE4 inhibitor CMPO by using tandem acylation/(3,3)-sigmatropic rearrangement. In comparison with the previous synthesis, this method afforded the required 3-oxymethyl-substituted 1,2-oxazine intermediate in a much higher yield $(76 \%$ vs. $27 \%)$. This key intermediate could be readily converted into the target (-)-CMPO by the reductive contraction of the 1,2-oxazine ring followed by deprotection and carbamylation with $\operatorname{Im}_{2} \mathrm{CO}$. A rapid epimerization of the C- 6 acetal moiety was observed upon the reduction of the 5,6-dihydro-4H-1,2-oxazine ring with $\mathrm{NaBH}_{3} \mathrm{CN}$ in acetic acid. DFT calculations suggest that the epimerization is favored by an unprecedented double anchimeric assistance from a remote acyloxy group and the nitrogen atom of the 1,2-oxazine ring.

Supplementary Materials: The following are available online: NMR spectra for compounds 10, 17, 18, 18' $, 19,20$ and CMPO, chiral phase HPLC chromatograms for rac-CMPO and (-)-CMPO, Cartesian coordinates, absolute energies for all optimized geometries.

Author Contributions: E.V.P. carried out synthesis, separation, and purification of compounds; I.S.G. performed DFT calculations; S.L.I. collaborated in the discussion and interpretation of the results, manuscript editing; A.Y.S. supervised the whole research, including conceptualization, methodology, data curation and original draft preparation. All authors have read and agreed to the published version of the manuscript.

Funding: This research was funded by the Russian Science Foundation (grant 17-13-01411).

Conflicts of Interest: The authors declare no conflict of interest. The funders had no role in the design of the study; in the collection, analyses, or interpretation of data; in the writing of the manuscript, or in the decision to publish the results.

\section{References}

1. Denmark, S.E.; Thorarensen, A. Tandem $[4+2] /[3+2]$ Cycloadditions of Nitroalkenes. Chem. Rev. 1996, 96, 137-166. [CrossRef] [PubMed]

2. Tabolin, A.A.; Sukhorukov, A.Y.; Ioffe, S.L.; Dilman, A.D. Recent Advances in the Synthesis and Chemistry of Nitronates. Synthesis 2017, 49, 3255-3268. [CrossRef]

3. Mukaijo, Y.; Yokoyama, S.; Nishiwaki, N. Comparison of Substituting Ability of Nitronate versus Enolate for Direct Substitution of a Nitro Group. Molecules 2020, 25, 2048. [CrossRef] [PubMed]

4. de Carvalho, L.L.; Burrow, R.A.; Pereira, V.L.P. Diastereoselective synthesis of nitroso acetals from (S,E)- $\gamma$-aminated nitroalkenes via multicomponent $[4+2] /[3+2]$ cycloadditions promoted by $\mathrm{LiCl}$ or $\mathrm{LiClO}_{4}$. Beilstein J. Org. Chem. 2013, 9, 838-845. [CrossRef] [PubMed]

5. Kano, T.; Yamamoto, A.; Song, S.; Maruoka, K. Catalytic asymmetric syntheses of isoxazoline-N-oxides under phase-transfer conditions. Chem. Commun. 2011, 47, 4358-4360. [CrossRef] [PubMed]

6. Koc, E.; Kwon, O. Total syntheses of heliotridane and pseudoheliotridane through nitrodiene-acrylate 6 $\pi$-electrocyclization/[3+2] cycloaddition. Tetrahedron 2017, 73, 4195-4200. [CrossRef]

7. Creech, G.S.; Kwon, O. Tandem 6 $\pi$-Electrocyclization and Cycloaddition of Nitrodienes to Yield Multicyclic Nitroso Acetals. J. Am. Chem. Soc. 2010, 132, 8876-8877. [CrossRef]

8. Zhu, C.-Y.; Deng, X.-M.; Sun, X.-L.; Zheng, J.-C.; Tang, Y. Highly enantioselective synthesis of isoxazoline N-oxides. Chem. Commun. 2008, 6, 738-740. [CrossRef]

9. Streitferdt, V.; Haindl, M.H.; Hioe, J.; Morana, F.; Renzi, P.; von Rekowski, F.; Zimmermann, A.; Nardi, M.; Zeitler, K.; Gschwind, R.M. Unprecedented Mechanism of an Organocatalytic Route to Conjugated Enynes with a Junction to Cyclic Nitronates. Eur. J. Org. Chem. 2019, 2019, 328-337. [CrossRef]

10. Jiang, H.; Elsner, P.; Jensen, K.L.; Falcicchio, A.; Marcos, V.; Jørgensen, K.A. Achieving Molecular Complexity by Organocatalytic One-Pot Strategies-A Fast Entry for Synthesis of Sphingoids, Amino Sugars, and Polyhydroxylated $\alpha$-Amino Acids. Angew. Chem. Int. Ed. 2009, 48, 6844-6848. [CrossRef]

11. Baiazitov, R.Y.; Denmark, S.E. Tandem $[4+2] /[3+2]$ Cycloadditions. In Methods and Applications of Cycloaddition Reactions in Organic Syntheses; Nishiwaki, N., Ed.; John Wiley \& Sons: Hoboken, NJ, USA, 2014; pp. 471-550. 
12. Denmark, S.E.; Martinborough, E.A. Enantioselective Total Syntheses of (+)-Castanospermine, (+)-6-Epicastanospermine, (+)-Australine, and (+)-3-Epiaustraline. J. Am. Chem. Soc. 1999, 121, 3046-3056. [CrossRef]

13. Denmark, S.E.; Thorarensen, A.; Middleton, D.S. Tandem $[4+2] /[3+2]$ Cycloadditions of Nitroalkenes. 9. Synthesis of (-)-Rosmarinecine. J. Am. Chem. Soc. 1996, 118, 8266-8277. [CrossRef]

14. Denmark, S.E.; Baiazitov, R.Y.; Nguyen, S.T. Tandem double intramolecular $[4+2] /[3+2]$ cycloadditions of nitroalkenes: Construction of the pentacyclic core structure of daphnilactone B. Tetrahedron 2009, 65, 6535-6548. [CrossRef] [PubMed]

15. Denmark, S.E.; Montgomery, J.I.; Kramps, L.A. Synthesis, X-ray Crystallography, and Computational Analysis of 1-Azafenestranes. J. Am. Chem. Soc. 2006, 128, 11620-11630. [CrossRef]

16. Denmark, S.E.; Montgomery, J.I. Synthesis of cis,cis,cis,cis-[5.5.5.4]-1-Azafenestrane with Discovery of an Unexpected Dyotropic Rearrangement. Angew. Chem. Int. Ed. 2005, 44, 3732-3736. [CrossRef]

17. For a review see: Sukhorukov, A.Y. C-H Reactivity of the $\alpha$-Position in Nitrones and Nitronates. Adv. Synth. Catal. 2020, 362, 724-754. [CrossRef]

18. Tishkov, A.A.; Lesiv, A.V.; Khomutova, Y.A.; Strelenko, Y.A.; Nesterov, I.D.; Antipin, M.Y.; Ioffe, S.L.; Denmark, S.E. 2-Silyloxy-1,2-oxazines, a New Type of Acetals of Conjugated Nitroso Alkenes. J. Org. Chem. 2003, 68, 9477-9480. [CrossRef]

19. Sukhorukov, A.Y.; Kapatsyna, M.A.; Yi, T.L.T.; Park, H.R.; Naumovich, Y.A.; Zhmurov, P.A.; Khomutova, Y.A.; Ioffe, S.L.; Tartakovsky, V.A. A General Metal-Assisted Synthesis of $\alpha$-Halo Oxime Ethers from Nitronates and Nitro Compounds. Eur. J. Org. Chem. 2014, 2014, 8148-8159. [CrossRef]

20. Naumovich, Y.A.; Buckland, V.E.; Sen'ko, D.A.; Nelyubina, Y.V.; Khoroshutina, Y.A.; Sukhorukov, A.Y.; Ioffe, S.L. Metal-assisted addition of a nitrate anion to bis(oxy)enamines. A general approach to the synthesis of $\alpha$-nitroxy-oxime derivatives from nitronates. Org. Biomol. Chem. 2016, 14, 3963-3974. [CrossRef]

21. Tabolin, A.A.; Lesiv, A.V.; Khomutova, Y.A.; Nelyubina, Y.V.; Ioffe, S.L. Rearrangement of 3-alkylidene-2-siloxy-tetrahydro-1,2-oxazines (ASENA). A new approach toward the synthesis of 3- $\alpha$-hydroxyalkyl-5,6-dihydro-4H-1,2-oxazines. Tetrahedron 2009, 65, 4578-4592. [CrossRef]

22. Naumovich, Y.A.; Golovanov, I.S.; Sukhorukov, A.Y.; Ioffe, S.L. Addition of HO-Acids to N,N-Bis(oxy)enamines: Mechanism, Scope and Application to the Synthesis of Pharmaceuticals. Eur. J. Org. Chem. 2017, 2017, 6209-6227. [CrossRef]

23. Zhmurov, P.A.; Khoroshutina, Y.A.; Novikov, R.A.; Golovanov, I.S.; Sukhorukov, A.Y.; Ioffe, S.L. Divergent Reactivity of In Situ Generated Metal Azides: Reaction with N,N-Bis(oxy)enamines as a Case Study. Chem. Eur. J. 2017, 23, 4570-4578. [CrossRef] [PubMed]

24. Zhmurov, P.A.; Sukhorukov, A.Y.; Chupakhin, V.I.; Khomutova, Y.V.; Ioffe, S.L.; Tartakovsky, V.A. Synthesis of PDE IV inhibitors. First asymmetric synthesis of two of GlaxoSmithKline's highly potent Rolipram analogues. Org. Biomol. Chem. 2013, 11, 8082-8091. [CrossRef] [PubMed]

25. Sukhorukov, A.Y.; Boyko, Y.D.; Ioffe, S.L.; Khomutova, Y.A.; Nelyubina, Y.V.; Tartakovsky, V.A. Synthesis of PDE IVb Inhibitors. 1. Asymmetric Synthesis and Stereochemical Assignment of (+)- and (-)-7-[3-(Cyclopentyloxy)-4-methoxyphenyl]hexahydro-3H-pyrrolizin-3-one. J. Org. Chem. 2011, 76, 7893-7900. [CrossRef] [PubMed]

26. Kokuev, A.O.; Antonova, Y.A.; Dorokhov, V.S.; Golovanov, I.S.; Nelyubina, Y.V.; Tabolin, A.A.; Sukhorukov, A.Y.; Ioffe, S.L. Acylation of Nitronates: [3,3]-Sigmatropic Rearrangement of in Situ Generated N-Acyloxy,N-oxyenamines. J. Org. Chem. 2018, 83, 11057-11066. [CrossRef]

27. Brackeen, M.F.; Stafford, J.A.; Cowan, D.J.; Brown, P.J.; Domanico, P.L.; Feldman, P.L.; Rose, D.; Strickland, A.B.; Veal, J.M.; Verghese, M. Design and Synthesis of Conformationally Constrained Analogs of 4-(3-Butoxy-4-methoxybenzyl)imidazolidin-2-one (Ro 20-1724) as Potent Inhibitors of cAMP-Specific Phosphodiesterase. J. Med. Chem. 1995, 38, 4848-4854. [CrossRef]

28. Jackson, E.K.; Carcillo, J.A. Treatment of Sepsis-Induced Acute Renal Failure. U.S. Patent 5849774, 15 December 1998.

29. Mulhall, A.M.; Droege, C.A.; Ernst, N.E.; Panos, R.J.; Zafar, M.A. Phosphodiesterase 4 inhibitors for the treatment of chronic obstructive pulmonary disease: A review of current and developing drugs. Exp. Opin. Investig. Drugs 2015, 24, 1597-1611. [CrossRef] 
30. Zhmurov, P.A.; Tabolin, A.A.; Sukhorukov, A.Y.; Lesiv, A.V.; Klenov, M.S.; Khomutova, Y.A.; Ioffe, S.L.; Tartakovsky, V.A. Synthesis of phosphodiesterase IVb inhibitors 2. Stereoselective synthesis of hexahydro-3H-pyrrolo[1,2-c]imidazol-3-one and tetrahydro-1H-pyrrolo[1,2-c][1,3]oxazol-3-one derivatives. Russ. Chem. Bull. 2011, 60, 2390-2395. [CrossRef]

31. Yasuo, T.; Norihiko, Y.; Hiroko, M.; Toshihide, K.; Masahiro, A.; Yutaka, M. Synthesis and a Novel Fragmentation of 6-Alkoxy-5,6-dihydro-4H-1,2-oxazine 2-Oxide. Bull. Chem. Soc. Jpn. 1988, 61, 461-465.

32. Sukhorukov, A.Y.; Ioffe, S.L. Chemistry of Six-Membered Cyclic Oxime Ethers. Application in the Synthesis of Bioactive Compounds. Chem. Rev. 2011, 111, 5004-5041. [CrossRef]

33. Zimmer, R.; Arnold, T.; Homann, K.; Reissig, H.-U. An Efficient and Simple Synthesis of 3,4,5,6-Tetrahydro-2H-1,2-oxazines by Sodium Cyanoborohydride Reduction of 5,6-Dihydro-4H-1,2-oxazines. Synthesis 1994, 1994, 1050-1056. [CrossRef]

34. Demchenko, A.V.; Rousson, E.; Boons, G.-J. Stereoselective 1,2-cis-galactosylation assisted by remote neighboring group participation and solvent effects. Tetrahedron Lett. 1999, 40, 6523-6526. [CrossRef]

35. Ma, Y.; Lian, G.; Li, Y.; Yu, B. Identification of 3,6-di-O-acetyl-1,2,4-O-orthoacetyl- $\alpha$-d-glucopyranose as a direct evidence for the 4-O-acyl group participation in glycosylation. Chem. Commun. 2011, 47, 7515-7517. [CrossRef] [PubMed]

36. Beaver, M.G.; Billings, S.B.; Woerpel, K.A. C-Glycosylation Reactions of Sulfur-Substituted Glycosyl Donors: Evidence against the Role of Neighboring-Group Participation. J. Am. Chem. Soc. 2008, 130, 2082-2086. [CrossRef] [PubMed]

37. Stalford, S.A.; Kilner, C.A.; Leach, A.G.; Turnbull, W.B. Neighbouring group participation vs. addition to oxacarbenium ions: Studies on the synthesis of mycobacterial oligosaccharides. Org. Biomol. Chem. 2009, 7, 4842-4852. [CrossRef] [PubMed]

38. Yang, B.; Yang, W.; Ramadan, S.; Huang, X. Pre-Activation-Based Stereoselective Glycosylations. Eur. J. Org. Chem. 2018, 2018, 1075-1096. [CrossRef]

39. Crich, D.; Hu, T.; Cai, F. Does Neighboring Group Participation by Non-Vicinal Esters Play a Role in Glycosylation Reactions? Effective Probes for the Detection of Bridging Intermediates. J. Org. Chem. 2008, 73, 8942-8953. [CrossRef]

40. Komarova, B.S.; Tsvetkov, Y.E.; Nifantiev, N.E. Design of $\alpha$-Selective Glycopyranosyl Donors Relying on Remote Anchimeric Assistance. Chem. Rec. 2016, 16, 488-506. [CrossRef]

Sample Availability: Samples of racemic and enantiopure PDE4 inhibitor CMPO are available from the authors.

(C) 2020 by the authors. Licensee MDPI, Basel, Switzerland. This article is an open access article distributed under the terms and conditions of the Creative Commons Attribution (CC BY) license (http://creativecommons.org/licenses/by/4.0/). 